\title{
Utilization of a Spray-Applied Calcium Bentonite Clay to Ameliorate the Effects of Low-Levels of Aflatoxinin Starter Broiler Diets Containing DDGS
}

\author{
Fowler $\mathrm{J}^{1 *}$, Hashim $\mathbf{M}^{1}$, Barrientos-Velazquez $\mathrm{A}^{2}$, Deng $\mathrm{Y}^{2}$ and Bailey $\mathrm{CA}^{1}$ \\ ${ }^{1}$ Department of Poultry Science, Texas A\&M University, College Station, TX, USA \\ ${ }^{2}$ Department of Soil and Crop Sciences, Texas A\&M University, College Station, TX, USA
}

\begin{abstract}
To evaluate the efficacy of a calcium bentonite clay for the amelioration of the effects of aflatoxin on broiler growth performance and relative organ weight, a total of 288 one-day old Ross 308 straight-run broilers were fed a commercial type corn-soy broiler starter diet formulated with $20 \%$ DDGS over a three-week rearing period. There is evidence that fermentation co-products can have increased mycotoxin concentrations than compared to the original grain. Four mash basal diets were prepared using various concentrations of clean corn and DDGS and aflatoxin-contaminated corn and DDGS and were found to contain 16, 228, 366 and $681 \mathrm{ppb}$ aflatoxin in the final feeds. Each diet was then blended with $0.5 \%$ of either a non-binding kaolinite or aflatoxin-binding calcium bentonite clay, which were sprayapplied as a liquid suspension during mixing. Weekly feed consumption and body weights per pen were recorded. On day 21 , all birds were killed and weighed individually, and the liver, kidney, spleen, and bursa of Fabricius from were weighed and relative organ weights were calculated. All data were analyzed as a $2 \times 4$ full-factorial with 2 sources of clay at 4 concentrations of aflatoxin. All levels of aflatoxin significantly $(p \leq 0.05)$ increased cumulative feed conversion and decreased broiler productivity index at 21 days of age. Relative liver weights were significantly increased by all aflatoxin levels. Relative kidney weights were significantly higher beginning at the $366 \mathrm{ppb}$ level. The relative spleen and bursa weights were unaffected. The inclusion of spray-applied bentonite clay had no effect on the toxicity of aflatoxin in this trial when compared to the non-binding kaolinite clay.
\end{abstract}

Keywords: Bentonite; Aflatoxin; Broiler; Chicken; DDGS

\section{Introduction}

With ethanol receiving considerable attention as a potential source for renewable fuel in recent years, corn prices have increased and the use of fermentation co-products, such as Distiller's Dried Grains and Solubles (DDGS), have become more common in animal feeds. Any mycotoxins contained in grain bound for fermentation will still appear in the co-products that end up in animal feeds [1]. In fact, fermentation and distillation can increase mycotoxin concentrations up to three-fold in corn-derived co-products [2].

Mycotoxins are secondary metabolites produced by certain fungal species (e. g. Aspergillus, Penicillium, and Fusarium). Within the family of mycotoxins, there are a variety chemical structures, biological properties, and levels of toxicity. Aflatoxins are a member of this mycotoxin family and are considered one of the most potent natural carcinogens. Of the categories of aflatoxin, aflatoxin B1 has the most potent biological effects. No animal species is immune to the effects of aflatoxin contamination in the diet. The Aspergillus species that produce aflatoxins are ubiquitous in the soil and are a common contaminant of feed crops in warm, humid climates. In poultry, aflatoxin exposure has been shown to have effects ranging fromreduced feed intake and weight gain, decreased egg production, immunosuppression, increased relative liver and kidney weights, impaired serum biochemistry, and ultimately mortality [3-6]. It has been demonstrated that aflatoxin exertsits toxic effects upon absorption in the gastrointestinal tract and bioactivation of the molecule in the liver. Aflatoxin B1undergoes epoxidation at the terminal furan ring ( 8,9 position) to form the carcinogenic metabolite aflatoxin B1-8,9 epoxide. Once activated into the epoxide, aflatoxin $\mathrm{B}_{1}$ can form adducts with DNA, RNA, and protein, inactivating tumor suppression and impairing protein synthesis and function [7].

Once produced, aflatoxins are relatively stable compounds that are not destroyed by conventional feed processing techniques. If improperly handled during harvest, transport, or storage, Aspergillus spp. can continue to produce more aflatoxin. Preventing the growth of aflatoxin-producing mold species on crops in the field would be an advisable strategy for reducing the incidence of aflatoxin contamination in feedstuffs. For example, the commercial product aflaguard $^{\mathrm{TM}}$ is designed to deliver spores of a nontoxic strain of $A$. flavus to offer protection in the field via competitive exclusion. However, in cases where such preventative management either cannot or has not occurred, poultry producers require cost-effective methods of detoxifying contaminated seed or grain. The use of non-nutritive, claybased adsorbents has proven effective at reducing the toxic effects of aflatoxins in various animal species. These various aluminosilicate and bentonite clays have been shown in vitro to bind aflatoxins in the interlayers of the clay structure as well as on the edge with relatively high affinity [7-9]. Once bound, the aflatoxins can pass through the gastrointestinal tract unabsorbed, thereby reducing the toxic effects. The inclusion of such clay-based binders has been shown in vivo to have a significant protective effect against aflatoxicosis in a variety of species [10-13].

The objective of the present study is to determine the protective efficacy of including a particular calcium bentonite clay as a wet, sprayapplication in the presence of dietary aflatoxin on the growth and performance of starting broilers fed diets containing 20\% DDGS.

\section{Materials and Methods}

${ }^{*}$ Corresponding author: Justin Fowler, Department of Poultry Science, Texas A\&M University, College Station, 101 Kleberg Center, College Station, TX, 778432472, USA, Tel: 979-845-1931; E-mail: fowlerj22@tamu. edu

Received February 10, 2014; Accepted February 20, 2014; Published February 25,2014

Citation: Fowler J, Hashim M, Barrientos-Velazquez A, Deng Y, Bailey CA (2014) Utilization of a Spray-Applied Calcium Bentonite Clay to Ameliorate the Effects of Low-Levels of Aflatoxinin Starter Broiler Diets Containing DDGS. Nat Prod Chem Res 2: 127 doi:10.4172/ 2329-6836.1000127

Copyright: @ 2014 Fowler J, et al. This is an open-access article distributed under the terms of the Creative Commons Attribution License, which permits unrestricted use, distribution, and reproduction in any medium, provided the original author and source are credited. 


\section{Diet formulation}

Aflatoxin for this trial was introduced by inoculating yellow dent corn and DDGS with live fungal cultures of Aspergillus parasiticus. Inoculated grains were incubated for five days at $37^{\circ} \mathrm{C}$ and then kept in a portable cement mixer under green-house conditions for one week with daily mixing. The contaminated grains were then assayed by the Office of the Texas State Chemist for total aflatoxin concentration and were determined to contain 6000 and $1400 \mathrm{ppb}$ for the corn and DDGS, respectively.

Dietary treatments were arranged as a complete $2 \times 4$ factorial design, with two clay sources at four concentrations of aflatoxin. Four mash basal diets (calculated to be isocaloric and isonitrogenous and to contain $20 \%$ DDGS) were prepared by blending various concentrations of the non-contaminated corn and DDGS with the aflatoxincontaminated corn and DDGS with a basal soybean meal concentrate such that there would be a 0, Low, Medium, and High aflatoxin treatment diet. Each diet was then sub-divided and blended with either $0.5 \%$ of Non-aflatoxin Binding kaolinite Clay (NBC) or high-affinity binding calcium bentoniteclay (TX4). The clays were applied as a water-suspension that was spray-applied to the treatment diets with a commercial paint sprayer during mixing. Composition of the basal diet is presented in Table 1.

HPLC analysis of samples of the NBC treatments diets by the Office of the Texas State Chemist found there to be 16, 228, 366, and 681 ppb in our 0, Low, Medium, and High aflatoxin groups, respectively. Previous work in our laboratory using NBC and TX4 clays have been at levels closer to $0,500,1000$, and $2000 \mathrm{ppb}$. So this study presented an opportunity to evaluate the efficacy of the TX4 calcium bentonite clay at ameliorating aflatoxicosis at relatively lower levels of aflatoxin.

\section{Growth and performance}

\begin{tabular}{|c|c|}
\hline Ingredient & Amount (\%) \\
\hline Corn & 46.44 \\
\hline DDGS & 20.00 \\
\hline Soybean meal $48 \%$ & 24.92 \\
\hline DL-methionine $98 \%$ & 0.21 \\
\hline Lysine $\mathrm{HCl}$ & 0.34 \\
\hline Fat, blended & 3.87 \\
\hline Limestone & 1.49 \\
\hline Monocalcium phosphate & 1.59 \\
\hline Salt & 0.35 \\
\hline Trace minerals $^{1}$ & 0.05 \\
\hline Vitamin premix $^{1}$ & 0.25 \\
\hline Clay $^{2}$ & 0.50 \\
\hline \multicolumn{2}{|l|}{ Nutrient Composition ${ }^{3}$} \\
\hline Crude Protein & 22.00 \\
\hline ME (Kcal/kg) & 3,050 \\
\hline Methionine & 0.56 \\
\hline Lysine & 1.31 \\
\hline Crude fat & 6.89 \\
\hline Crude fiber & 3.24 \\
\hline Calcium & 0.95 \\
\hline Non-phytate phosphorous & 0.45 \\
\hline Sodium & 0.22 \\
\hline
\end{tabular}

${ }^{1}$ Vitamins and trace minerals were added at a level to meet or exceed the NRC (1994) requirements for starting broilers

${ }^{2}$ Kaolinte clay was added as non-binding, control clay. A calcium bentonite was added as aflatoxin-binding treatment clay

${ }^{3}$ Nutrient values are calculated

Table 1: Composition of the basal diet.
A total of 288 straight-run, Ross 308 broiler chicks obtained on the day of hatch were randomly assigned to 48 battery-brooder pens (six birds per pen, six pen replicates per eight dietary treatments) such that the initial weight per pen would be $\pm 10 \mathrm{~g}$ of the mean weight per pen. Birds were allowed ad libitum access to feed and water for 21 days. Feed consumption and body weight per pen were recorded weekly. Mortality was checked for and monitored daily. Upon termination, the organ weights for the liver, kidney, spleen, and bursa of Fabricius were collected and relative organ weights were calculated on a per bird basis.

\section{Data analysis}

All data were analyzed as a $2 \times 4$ full-factorial using the General Linear Model procedure of SPSS. Means for significant main effects were separated using Duncan's Multiple Range Tests at a significance defined at $\mathrm{p} \leq 0.05$.

\section{Results}

The results for the growth parameters are presented in Table 2. Aflatoxin-inclusion had no effect on BW after 7 days. However, there was a significant main effect for the FCR beginning at the $200 \mathrm{ppb}$ level, which was significantly higher than $0 \mathrm{ppb}$. The same effect was not seen for the cumulative FCR at 14 days, nor was there an effect on BW. Upon termination at 21 days of age, there was still no main effect for aflatoxininclusion on BW. The cumulative FCR was significantly increased equally by all three aflatoxin levels relative to $0 \mathrm{ppb}$. Further, a broiler productivity index was calculated (Livability $[\%] \times$ Live weight $[\mathrm{kg}] /$ age $[\mathrm{d}] / \mathrm{FCR} \times 100$ ), which was significantly reduced by the inclusion of aflatoxin at any of the three levels. There was no significant difference between clay-typesfor any variable at any of the three weeks. There was also no aflatoxin clay interaction at any point.

The relative organ weights taken at 21 days of age are presented in Table 3. The presence of aflatoxin significantly increased relative liver weights beginning at the $200 \mathrm{ppb}$ level, and again at $400 \mathrm{ppb}$. The 600 $\mathrm{ppb}$ level was not significantly different from the two lower levels. Relative kidney weights were significantly increased at $400 \mathrm{ppb}$, and kidney weights from the $600 \mathrm{ppb}$ level were significantly higher than the $200 \mathrm{ppb}$. The spleen and bursa of Fabricius were unaffected. The inclusion of the spray-applied TX4 clay had no significant effect on the weights of any of the organs when compared to NBC. There was also no aflatoxin clay interaction.

\section{Discussion}

This study evaluated the effects of relatively lower levels of aflatoxin $(<1000 \mathrm{ppb})$ on starter broiler performance and relative organ weights. Although weight gain was unaffected by aflatoxin, there were negative effects on feed conversion and productivity index and there was an increase in the relative weights of the liver and kidney. In this study, after 21 days on treatment diets, body weights between the $0 \mathrm{ppb}$ treatment and the $600 \mathrm{ppb}$ treatment only varied by $4 \%$. In most cases in the literature where reductions in BW are reported, levels of aflatoxin in the feed are greater than $1000 \mathrm{ppb}$, whereas in this study all levels were less than $1000 \mathrm{ppb}$.

Feed conversion can often present an inconsistent measure of aflatoxicosis. Most often, it is found that feed consumption significantly decreases in conjunction with weight gain, leaving the FCR unchanged. Miazzo et al. [14] fed 2500 ppb aflatoxin to male broilers for 3 weeks beginning when the birds were 3 weeks of age. The researchers observed a significant reduction in weight gain but saw no effect on FCR. In two separate trials, Raju et al. [3] fed $300 \mathrm{ppb}$ aflatoxin to broilers for 6 weeks. In both trials, there were significant reductions 


\begin{tabular}{|c|c|c|c|c|c|c|c|}
\hline & \multicolumn{2}{|c|}{ Day 7} & \multicolumn{2}{|c|}{ Day 14} & \multicolumn{3}{|c|}{ Day 21} \\
\hline & BW & FCR & BW & FCR & BW & FCR & $\mathrm{PI}$ \\
\hline NBC & $186 \pm 1.4$ & $1.04 \pm 0.01$ & $460 \pm 8.2$ & $1.30 \pm 0.01$ & $834 \pm 12.4$ & $1.55 \pm 0.02$ & $252 \pm 7.2$ \\
\hline TX4 & $184 \pm 1.7$ & $1.05 \pm 0.01$ & $464 \pm 4.2$ & $1.30 \pm 0.02$ & $822 \pm 10.1$ & $1.57 \pm 0.02$ & $242 \pm 6.0$ \\
\hline$<20$ ppb & $186 \pm 2.9$ & $1.02 \pm 0.01^{a}$ & $478 \pm 6.6$ & $1.28 \pm 0.04$ & $856 \pm 15.5$ & $1.47 \pm 0.01^{a}$ & $274 \pm 7.0^{a}$ \\
\hline $200 \mathrm{ppb}$ & $183 \pm 2.0$ & $1.08 \pm 0.01^{c}$ & $455 \pm 14.7$ & $1.29 \pm 0.01$ & $819 \pm 21.6$ & $1.57 \pm 0.02^{\mathrm{b}}$ & $245 \pm 8.8^{b}$ \\
\hline $400 \mathrm{ppb}$ & $184 \pm 1.7$ & $1.04 \pm 0.01^{\mathrm{ab}}$ & $456 \pm 6.5$ & $1.31 \pm 0.01$ & $814 \pm 11.6$ & $1.61 \pm 0.04^{b}$ & $229 \pm 9.7^{b}$ \\
\hline $600 \mathrm{ppb}$ & $186 \pm 2.1$ & $1.05 \pm 0.01^{b}$ & $458 \pm 4.8$ & $1.31 \pm 0.01$ & $822 \pm 12.3$ & $1.58 \pm 0.02^{b}$ & $239 \pm 7.4^{b}$ \\
\hline \multicolumn{8}{|l|}{ ANOVA } \\
\hline Aflatoxin & 0.800 & $<0.001$ & 0.238 & 0.623 & 0.258 & 0.001 & 0.004 \\
\hline Clay & 0.342 & 0.340 & 0.695 & 0.804 & 0.446 & 0.339 & 0.245 \\
\hline Aflatoxin ${ }^{*}$ Clay & 0.969 & 0.518 & 0.446 & 0.462 & 0.543 & 0.882 & 0.853 \\
\hline
\end{tabular}

${ }^{1}$ Data are presented as means \pm SEM

a,b,cMeans for main effects within a column lacking a common superscript differ $(P \leq 0.05)$

$\mathrm{BW}=$ Average body weight per bird $(\mathrm{g})$

FCR=Cumulative feed-to-gain ratio

$\mathrm{PI}=$ Broiler Productivity Index (Livability [\%]×Live weight $[\mathrm{kg}] /$ age $[\mathrm{d}] / \mathrm{FCR} \times 100$ )

Table 2: Growth parameters.

\begin{tabular}{|c|c|c|c|c|}
\hline & Liver Wt (\%) & Kidney Wt (\%) & Spleen Wt (\%) & Bursa Wt (\%) \\
\hline NBC & $2.79 \pm 0.04$ & $0.81 \pm 0.01$ & $0.09 \pm 0.002$ & $0.28 \pm 0.01$ \\
\hline TX4 & $2.78 \pm 0.04$ & $0.82 \pm 0.01$ & $0.09 \pm 0.002$ & $0.28 \pm 0.01$ \\
\hline$<20 \mathrm{ppb}$ & $2.63 \pm 0.05^{\mathrm{a}}$ & $0.77 \pm 0.02^{\mathrm{a}}$ & $0.09 \pm 0.004$ & $0.29 \pm 0.01$ \\
\hline $200 \mathrm{ppb}$ & $2.78 \pm 0.05^{\mathrm{b}}$ & $0.80 \pm 0.02^{\mathrm{ab}}$ & $0.09 \pm 0.003$ & $0.27 \pm 0.01$ \\
\hline $400 \mathrm{ppb}$ & $2.94 \pm 0.06^{\mathrm{c}}$ & $0.83 \pm 0.02^{\mathrm{bc}}$ & $0.09 \pm 0.003$ & $0.28 \pm 0.01$ \\
\hline $600 \mathrm{ppb}$ & $2.82 \pm 0.06^{\mathrm{bc}}$ & $0.87 \pm 0.02^{\mathrm{c}}$ & $0.08 \pm 0.003$ & $0.28 \pm 0.01$ \\
\hline ANOVA & & & & \\
\hline Aflatoxin & 0.001 & 0.001 & 0.219 & 0.126 \\
\hline Clay & 0.862 & 0.665 & 0.633 & 0.528 \\
\hline Aflatoxin ${ }^{*}$ Clay & 0.882 & 0.939 & 0.429 & 0.771 \\
\hline
\end{tabular}

${ }^{1}$ Data are presented as means \pm SEM

a,b,c Means for main effects within a column lacking a common superscript differ ( $\mathrm{P} \leq$ 0.05)

Organ weights are presented as a percent of the body weight

Table 3: Organ collection (21 days of age)

in feed consumption and weight gain but no effect on FCR. Zhao et al. [5] reported no effect on feed conversion by 1000 or $2000 \mathrm{ppb}$ aflatoxin fed to straight-run broilers for 3 weeks. However, feed consumption was reduced by $1000 \mathrm{ppb}$ and was further reduced by $2000 \mathrm{ppb}$. In this study, FCR was increased by 200 ppb aflatoxin after 3 weeks on treatment diets, while body weight was unaffected. This supports the conclusion that FCR should not be considered in isolation from the other production parameters with respect to aflatoxin exposure.

Along with reductions in growth rate, liver damage is a common effect that has been associated with aflatoxicosis since it was first characterized $[15,16]$. In this study, both the relative liver weights and relative kidney weights were significantly increased by aflatoxin. Organ weights appear to be more sensitive to aflatoxin exposure when compared with body weight or feed consumption.

The inclusion of TX4as a spray-applied clay amendment to treatment diets did not offer any amelioration for the main effects of aflatoxin dose when compared to treatment diets containing the NBC. Previous reports that included the same concentration of a clay-based binder found that the additives offer significant protection against the effects of aflatoxin. In Gowda et al. [4], broilers fed $0.5 \%$ of a hydrated sodium-calcium aluminosilicate in diets containing $1000 \mathrm{ppb}$ aflatoxin showed significant improvements in the weight gain and relative liver weights at three weeks of age. Kermanshai et al. [17] found that $0.5 \%$ of a sodium bentonite offered significant amelioration against the effects
$1000 \mathrm{ppb}$ aflatoxin had on weight gain for three-week old broilers. However, since the $500 \mathrm{ppb}$ aflatoxin treatment had no effect on weight gain, the efficacy of the sodium bentonite at that level could not be determined. Aflatoxin levels in this trial were all less than $1000 \mathrm{ppb}$, which may explain the lack of main effects of the clay inclusion.

The use clay-based adsorbents have proven effective at binding aflatoxin with relatively high affinity in vitro and at reducing the toxic effects of aflatoxin in various animal species in vivo. Evaluating the efficacy of clay-based binders as possible interventions for ameliorating aflatoxicosis in animal feeds cannot be experimentally demonstrated in trials where relatively low-levels of aflatoxin do not produce significant main effects. However, feeding larger doses of aflatoxin to obtain a higher level of confidence will subject the additive to a scenario that is less representative of a "real world" situation. This particular sprayapplied calcium bentonite clay included at $0.5 \%$ of the diet did not ameliorate the toxicity caused by aflatoxin levels less than $1000 \mathrm{ppb}$.

\section{References}

1. Lillehoj EB, Lagoda A, Maisch WF (1979) The fate of aflatoxin in naturally contaminated corn during the ethanol fermentation. Can J Microbiol 25: 911-914.

2. Wu F, Munkvold GP (2008) Mycotoxins in ethanol co-products: modeling economic impacts on the livestock industry and management strategies. J Agric Food Chem 56: 3900-3911.

3. Raju MV, Rama Rao SV, Radhika K, Panda AK (2005) Effect of amount and source of supplemental dietary vegetable oil on broiler chickens exposed to aflatoxicosis. Br Poult Sci 46: 587-594.

4. Gowda NK, Ledoux DR, Rottinghaus GE, Bermudez AJ, Chen YC (2008) Efficacy of turmeric (Curcuma longa), containing a known level of curcumin, and a hydrated sodium calcium aluminosilicate to ameliorate the adverse effects of aflatoxin in broiler chicks. Poult Sci 87: 1125-1130.

5. Zhao J, Shirley RB, Dibner JD, Uraizee F, Officer M, et al. (2010) Comparison of hydrated sodium calcium aluminosilicate and yeast cell wall on counteracting aflatoxicosis in broiler chicks. Poult Sci 89: 2147-2156.

6. Lee JT, Jessen KA, Beltran R, StarkI V, Schatzmayr G, et al. (2012) Mycotoxincontaminated diets and deactivating compound in laying hens: 1 . effects on performance characteristics and relative organ weight. Poult Sci 91: 2089-2095.

7. Phillips TD (1999) Dietary clay in the chemoprevention of aflatoxin-induced disease. Toxicol Sci 52: 118-126.

8. Desheng Q, Fan L, Yanhu Y, Niya Z (2005) Adsorption of aflatoxin B1 on montmorillonite. Poult Sci 84: 959-961.

9. Kannewischer I, Tenorio AMG, White GN, Dixon JB (2006) Smectite clays as adsorbents of aflatoxin B1: Initial steps. Clay Sci 12: 199-204.

10. Kubena LF, Harvey RB, Phillips TD, Corrier DE, Huff WE (1990) Diminution of aflatoxicosis in growing chickens by the dietary addition of a hydrated, sodium 
Citation: Fowler J, Hashim M, Barrientos-Velazquez A, Deng Y, Bailey CA (2014) Utilization of a Spray-Applied Calcium Bentonite Clay to Ameliorate the Effects of Low-Levels of Aflatoxinin Starter Broiler Diets Containing DDGS. Nat Prod Chem Res 2: 127 doi:10.4172/ 2329-6836.1000127

calcium aluminosilicate. Poult Sci 69: 727-735.

11. Huff WE, Kubena LF, Harvey RB, Phillips TD (1992) Efficacy of hydrated sodium calcium aluminosilicate to reduce the individual and combined toxicity of aflatoxin and ochratoxin A. Poult Sci 71: 64-69.

12. Kubena LF, Harvey RB, Huff WE, Elissalde MH, Yersin AG, et al. (1993) Efficacy of a hydrated sodium calcium aluminosilicate to reduce the toxicity of aflatoxin and diacetoxyscirpenol. Poult Sci 72: 51-59.

13. Kubena LF, Harvey RB, Bailey RH, Buckley SA, Rottinghaus GE (1998) Effects of a hydrated sodium calcium aluminosilicate (T-Bind) on mycotoxicosis in young broiler chickens. Poult Sci 77: 1502-1509.

14. Miazzo R, Rosa CA, De QueirozCarvalho EC, Magnoli C, Chiacchiera SM, et al. (2000) Efficacy of synthetic zeolite to reduce the toxicity of aflatoxin in broiler chicks. Poult Sci 79: 1-6.

15. Smith JW, Hamilton PB (1970) Aflatoxicosis in the broiler chicken. Poult Sc 49: 207-215.

16. Huff WE, Kubena LF, Harvey RB, Corrier DE, Mollenhauer HH (1986) Progression of aflatoxicosis in broiler chickens. Poult Sci 65: 1891-1899.

17. Kermanshahi H, Hazegh AR, Afzali N (2009) Effect of Sodium Bentonite in Broiler Chickens fed Diets Contaminated with Aflatoxin B1. Journal of Animal and Veterinary Advances 8: 1631-1636. 